\title{
Specific challenge testing for occupational asthma: revised handbook
}

\author{
Hille Suojalehto ${ }^{1}$, Katri Suuronen ${ }^{1}$ and Paul Cullinan ${ }^{2}$ \\ Affiliations: ${ }^{1}$ Finnish Institute of Occupational Health, Helsinki, Finland. ${ }^{2}$ Occupational and Environmental \\ Medicine, Imperial College School of Medicine, National Heart and Lung Institute, London, UK. \\ Correspondence: Hille Suojalehto, Finnish Institute of Occupational Health, Occupational Medicine Team, \\ Topeliksenkatu 41 a A, PO Box 40, FI-00032 Työterveyslaitos, Finland. E-mail: hille.suojalehtodattl.fi
}

@ERSpublications

Specific inhalation challenge is considered a reference standard in the diagnosis of occupational asthma. An updated handbook of challenge techniques for a large number of sensitising agents from 11 European centres is now available. http://bit.ly/2XVpW1P

Cite this article as: Suojalehto H, Suuronen K, Cullinan P. Specific challenge testing for occupational asthma: revised handbook. Eur Respir J 2019; 54: 1901026 [https://doi.org/10.1183/13993003.01026-2019].

When undertaken carefully, and in experienced hands, specific inhalation challenge (SIC) testing is widely considered to be the reference standard in the diagnosis of occupational asthma. In 2013 the European Respiratory Society commissioned a pan-European task force to produce standards for the conduct and interpretation of SIC with the aim of sharing expertise among those centres who offer the service and with centres who wish to develop a new service. The findings and recommendations of the taskforce were published in the European Respiratory Journal [1].

Alongside the main report, we produced a handbook of challenge techniques for a large number of different sensitising agents, including both those of high and low molecular mass. We committed ourselves to provide an update within 5 years; this has been completed, as planned, and is presented as a supplementary file to this editorial. The techniques are those used in 11 specialist centres and are listed by agent category with contact information for each centre should practitioners require more detailed information; the occupational asthma community in Europe prides itself on being collaborative, and collectively is happy to share its experience and expertise.

Controlled, experimental SIC was first developed - formally, as a diagnostic tool for occupational asthma around 50 years ago, in a single centre. Its practice has flourished and spread since but it is fair to say that access remains patchy, with some European countries, and many regions within them, having no provision at all. This disadvantages patients who require the highest standard of diagnostic accuracy, employers who need to know which of the agents in their workplaces is giving rise to disease in their workers, and regulators charged with controlling what is essentially a preventable disease. Moreover, it hampers the identification of novel sensitisers and the exploration of the mechanisms behind their sensitising properties; this is, perhaps, especially important in the study of chemical sensitisers and particularly so since, rightly or wrongly, they are now considered Substances of Very High Concern under REACH. For these reasons we encourage respiratory physicians and the commissioners of healthcare to familiarise themselves with the relevant guidelines and to consider the equitable provision of SIC across Europe wherever the resources to perform SIC safely and with high quality can be ensured. 
Conflict of interest: None declared.

\section{Reference}

1 Vandenplas O, Suojalehto $\mathrm{H}$, Aasen TB, et al. Specific inhalation challenge in the diagnosis of occupational asthma: consensus statement. Eur Respir J 2014; 43: 1573-1587. 